\title{
Through the Linguistic Silk Road
}

\section{The exchange between Cognitive Sociolinguistics and Chinese Linguistics, and its future prospects}

\begin{abstract}
Cognitive Sociolinguistics, an enterprise that emerged from the West end of Eurasia, has been enjoying increasing popularity in China. With its commitment to converge Cognitive Linguistics and sociolinguistics, this field has been providing studies of Chinese linguistics with theoretical and methodological inspirations. Chinese Linguistics, in turn, has also advanced Cognitive Sociolinguistics with many of its novel findings. This exchange not only helped bring previously isolated domains of Chinese Linguistics together into a more integrated framework, but also expanded the horizon of CS whose previous focus was mainly restricted to Indo-European data. The review takes stock of these advances along three dimensions of Cognitive Sociolinguistics (i.e., lexical-semantic, constructional, and attitudinal/acquisitional variation) in the context of Chinese linguistics, and discusses future research trajectories along which the exchange between the two fields can further benefit each other.
\end{abstract}

Keywords: Cognitive Sociolinguistics, Chinese linguistics, variation studies

Acknowledgement: Work on this paper was supported by a China Scholarship Council grant to the first author (grant No. CSC201906900122) and a Marie Skłodowska-Curie Individual Fellowship (of European Union's Horizon 2020 research and innovation program) to the second author (grant No. 793920).

\section{Introduction}

As an enterprise that converges Cognitive Linguistics and the tradition of sociolinguistics, the field of Cognitive Sociolinguistics (hereinafter CS) has been cultivating research into the socio-cognitive aspects of language from a usage-based

\footnotetext{
Yi Li, KU Leuven, Blijde-Inkomststraat 21, Leuven, Belgium, e-mail: yi.li1@kuleuven.be Weiwei Zhang, KU Leuven and Shanghai International Studies University, Blijde-Inkomststraat 21, Leuven, Belgium, e-mail: weiwei.zhang@kuleuven.be
}

D Open Access. (C) 2021 Yi Li, Weiwei Zhang, published by De Gruyter. (c) BY-NC-ND This work is licensed under the Creative Commons Attribution-NonCommercial-NoDerivatives 4.0 License. 
perspective and investigating the cognitive and sociocultural driving forces of language variation and change. The past decade has witnessed an increasing number of volumes dedicated to the advances of CS (e.g., Kristiansen and Dirven 2008; Geeraerts et al. 2010a; Kristiansen and Geeraerts 2013; Pütz et al. 2014). A wide spectrum of topics have been covered, including not only lexical (e.g. Geeraerts and Speelman 2010; Peirsman et al. 2010) and grammatical variation (e.g., Stefanowitsch and Gries 2008; Szmrecsanyi 2010), but also more applied aspects such as language attitudes and acquisition (e.g., Kristiansen 2008, 2010; Pantos 2014), language policy (e.g., Polzenhagen and Dirven 2008), cultural models of language (e.g., Schneider 2014), and World Englishes (e.g., Wolf and Polzenhagen 2009, 2014). At the same time, CS research, which can be narrowly characterized as study of language variation from the combined perspective of social and cognitive constraints (Hollmann 2013), has been enjoying growing popularity as theoretical and methodological underpinnings for Chinese Linguistics. Scholars of Chinese Linguistics have paid attention to the emergence of CS from the beginning (Sun 2009; Zhang and Zhou 2010), and have been offering constant reviews of the state of the art (e.g., Zhou 2012; Fang and Zhang 2015; Zhang 2019).

Situated in this context, this article aims to examine how the exchange between CS and Chinese Linguistics has brought mutual benefits to each other. We first survey how CS has stimulated recent variationist studies in Chinese Linguistics. The achievements are examined following the three research dimensions in Geeraerts et al. (2010b), viz., the dimensions of lexical semantic variation, grammatical and constructional variation, and attitudinal/acquisitional variation. Then, the article discusses how Chinese Linguistics can benefit CS itself. Finally, the article sketches out future prospects that may bode further cooperation for the two fields.

\section{How has CS Benefited Chinese Linguistics?}

Over the more than 10 years of exchange between CS and Chinese Linguistics, what are the wools the former brought to the latter? Firstly, CS, with its fundamental emphasis of meaning variation (Geeraerts et al. 2010b: 6-7), has inspired more semantically enriched research in variationist Chinese Linguistics, which previously focused primarily on phonetic variation within one variety/dialect (e.g., Chen 1993; Xu et al. 1993; Zhang 2014), or across varieties/dialects (e.g., Li 2004). Beyond doubt, without a systematic investigation of lexical and grammatical variation, we could not have a clear picture of language variation as a whole. Secondly, CS has also propelled Chinese Linguistics to analyze its rich lectal 
varieties more systematically. Despite of the rich varieties of Mandarin Chinese ${ }^{1}$ and the many dialects spoken within China, past studies have been generally restricted to the special features in one variety (e.g., Chen 1986; Wang 1999), or comparing differences between two varieties (e.g., Shi et al. 2006, 2014). Departing from these isolated studies, CS-informed Chinese Linguistics could examine a wider range of lectal variation and its cognitive and socio-cultural constraints. Thirdly, the traditional approach in research on varieties of Chinese often involves small-scale survey-based methods with geographical dimension as its core question. Other dimensions (e.g., social, economic, demographic) are still largely overlooked by Chinese linguists. The methodological underpinnings of CS allow us to employ advanced quantitative approaches for measuring the lexical and grammatical variability along a multitude of dimensions. So far, an increasing number of studies have been conducted in the framework of CS to investigate linguistic phenomena in Chinese. We will present some representative works along the following three dimensions.

\subsection{The lexical semantic dimension}

Variationist lexical semantic studies grounded in CS are usage-based, placing centrally the role of the speaker, the context of the communication, and the produced utterances. Studies along this dimension mainly focus on issues including geographical, social-stratificational, and conceptual factors that contribute to lexical variation (e.g., Speelman et al. 2008; Geeraerts and Speelman 2010; Soares da Silva 2010), and the quantitative methods of measuring lexical distance between language varieties (e.g., Speelman et al. 2003; Ruette et al. 2011).

Within this dimension, studies in Chinese Linguistics have chosen variation in metonymy as their primary interests. Synchronically, place name metonymies have been investigated from a cross-lectal perspective (Zhang et al. 2011; Zhang et al. 2018). Diachronically, Zhang et al. (2015) analyzes the variation in metonymic patterns for WOMAN across a time span of 2,000 years. More recently, with an increasing interest on the methodological advances of lectometric study on language variation, researchers start exploring the lexical variation in Chinese varieties by performing large-scale quantitative aggregation (see Heylen and Zhang 2019; Zhang et al. 2019).

1 Mandarin Chinese is the official language in China (being referred to as putonghua in Mainland, Hong Kong and Macau SAR or guoyu in Taiwan) and Singapore (huayu). It is also one of the languages of instruction in Malaysia. 


\subsection{The constructional dimension}

Recent efforts in this dimension follow the long and established tradition of variationist studies in syntactic alternations (e.g., Sankoff and Thibault 1981; Weiner and Labov 1983) and have illustrated the subtle and stochastic variability of syntactic choices both within and across varieties of a certain language. It has been shown that speakers' selections of syntactic variants are constrained by various lectal factors such as region (e.g., Bresnan and Hay 2008; Szmrecsanyi et al. 2016; Röthlisberger et al. 2017), time (e.g., Wolk et al. 2013), and register (e.g., Gries 2013; Grafmiller 2014).

In this dimension, Chinese scholars have mainly investigated variation in grammatical alternations in different lects of Chinese. Applying corpus-based data and various statistical modeling techniques, these studies have revealed a wide array of lectal constraints on syntactic variation. For instance, Zhang and Wang (2017) discovered the effect of register on selecting passive markers, in which rang is favored with written texts while gei is favored with spoken texts. Li et al. (submitted) takes a diachronic approach and diagnoses significant interactions between time period and two language-internal factors (i.e., end-weight and recipient animacy) influencing the theme-recipient alternation. And studies on causative construction alternation (Tian and Zhang 2020; Tian et al. 2022) have indicated significant regional variation with regard to the preference of the causative markers in Mainland, Taiwan, and Singapore Chinese.

\subsection{The attitudinal and acquisitional dimension}

The question of how accents and dialects are perceived takes center stage in sociolinguistic research into language attitudes. Traditional studies in this regard, for instance, have revealed listeners' usually negative perceptions of foreign accents (e.g., Lippi-Green 1997), and more recent usage-based evaluations suggest that accents are capable of activating socially stereotyped images that function as cognitive reference for speakers and listeners active positioning of him/herself regionally and socially (Kristiansen 2003; 2008). A growing number of CS-fueled research is dedicated to the variationist scrutiny of language attitudes and acquisition (e.g., Kristiansen 2010; Pantos 2014), attempting to shed light on how perceptions of accents and dialects differ as a function of different social variables such age, gender, and geography.

So far, Chinese studies along this dimension have been scarce. A heuristic effort is made in Xiong (2020), which presents a CS-based analysis of how Chinese listeners perceive both Chinese speakers' Mandarin accents (e.g., Beijing, 
Shanghai) and foreign speakers' Mandarin accents (e.g., American, Russian). Despite of the lack of research on Chinese under this framework, we do observe a growing volume of case studies that explore the perception of Mandarin accents over the past few years. Zhao $(2017$; 2019), for instance, examined listeners' perception of the variation of linguistic features in standard Mandarin variety, while several non-standard accents of Mandarin and their perceptions are discussed in Wang (2017) and Zhao and Liu (2020). We thus maintain that there is huge potential for future collaboration between variationist studies of Mandarin accents and research on the attitudinal dimension of CS. Further variationist studies, which take various social constraints into a more holistic account, will greatly deepen our understanding of how (non)standard accents of Mandarin are perceived and what factors contribute to those different perceptions.

Furthermore, we wish to note that the acquisitional dimension is also understudied and necessary to better understand if and how age is an important factor in the identification and perception of Chinese accents (cf., Kristiansen 2010), for which future studies need to involve young children participants of different age groups and upbringings.

\section{How can CS Benefit from Chinese Linguistics?}

Having discussed all the achievements of Chinese Linguistics inspired by CS, what can be the silk returned from CS-informed Chinese Linguistics? We hold that the results obtained from such studies of Chinese can at least help answer a crucial question of CS, viz., are the findings attested in previous CS studies typically Indo-European, or do they also hold for other language areas? Despite of the increasing volume of CS research on Chinese, most studies in this framework so far have relied on data from Indo-European languages. Such limitations may lead to theories biased towards Indo-European languages, as is the case with previous studies in Cognitive Linguistics. Cross-linguistic evidence enables CS to discover what lectal variation is recurrent and what is different in distinct languages across the world, and already we can see some fruitful results from the collaboration between CS and Chinese Linguistics. For instance, Xiong's (2020) largescale experiment in Chinese listeners' perceptions of non-native Mandarin speakers reinforces previous findings of native speakers' negative assessments of nonnative accents (cf., Kristiansen 2010), and the diachronic fluidity regarding the predictive strength of animacy and end-weight on word order detected in Wolk et al. (2013) is identified again in a similar grammatical analysis in Li et al. 
(submitted). In a word, CS-informed Chinese Linguistics returns ideal typological evidence for testing the theoretical and methodological robustness of CS.

Furthermore, CS can also benefit from the more general domain of Chinese Linguistics, given that the language is characterized by many features that are not so prominent in the languages usually studied in the field (e.g., Dutch, English, and Spanish). Structurally, written Chinese plays a different role than in languages with an alphabetic writing system. Socially, Chinese also deviates from European languages with its stronger role of explicit, top-down language policies, and the size as a major, "regionally global” language. All these characteristics add significantly to the spectrum of linguistic situations studied from a CS point of view.

\section{Future prospects}

The exchange between CS and Chinese Linguistics has unveiled some intriguing findings across different dimensions of language variation, which paves ways for numerous potentials of future exploration. Two possible extensions are postulated for the collaboration. The first possible theoretical extension calls for more systemic CS-informed investigations of lexical, grammatical, and attitudinal variation. It is only by such endeavors can we obtain a more holistic picture of variation in Chinese. To this end, future CS research on Chinese can be based on the application of more diversified data sources with enriched lectal information. Possible resources include the Tagged Chinese Gigaword Corpus (Huang 2009), the LIVAC Corpus (Tsou and Kwong 2015), and the Global Chinese Corpus (Liu 2019). The second extension concerns the better methods of measuring linguistic distance between lects in Chinese, and we see recent corpus-based advances in lectometry (Heylen et al. 2015; De Pascale 2019) and Variation-Based Distance \& Similarity Modeling (VADIS, Szmrecsanyi et al. 2019) as welcome additions to the existing toolkit. 


\section{References}

Bresnan, Joan \& Jennifer Hay. 2008. Gradient grammar: An effect of animacy on the syntax of give in New Zealand and American English. Lingua 118(2). 245-259.

Chen, Chung-Yu. 1986. Grammatical features of Singapore Chinese. Yuyan Yanjiu 1. 138-152.

Chen, Zhongmin. 1993. The features of dialect contact and its methodology: From the perspective of some synchronic dissimilarities in Shanghai dialects. Yuyan Yanjiu 1. 120-127.

De Pascale, Stefano. 2019. Token-based vector space models as semantic control in lexical lectometry. Leuven: KU Leuven PhD dissertation.

Fang, Na \& Weiwei Zhang. 2015. Language variation research from a Cognitive Sociolinguistic perspective: A statistical analysis based on a survey of recent research papers. Zhongguo Shehui Yuyanxue 1. 69-79.

Geeraerts, Dirk, Gitte Kristiansen \& Yves Peirsman (eds.). 2010a. Advances in Cognitive Sociolinguistics. Berlin/New York: Mouton de Gruyter.

Geeraerts, Dirk, Gitte Kristiansen \& Yves Peirsman. 2010b. Introduction: Advances in Cognitive Sociolinguistics. In Dirk Geeraerts, Gitte Kritiansen \& Yves Peirsman (eds.), Advances in Cognitive Sociolinguistics, 1-20. Berlin/New York: Mouton de Gruyter.

Geeraerts, Dirk \& Dirk Speelman. 2010. Heterodox concept features and onomasiological heterogeneity in dialects. In Dirk Geeraerts, Gitte Kritiansen \& Yves Peirsman (eds.), Advances in Cognitive Sociolinguistics, 23-40. Berlin/New York: Mouton de Gruyter.

Grafmiller, Jason. 2014. Variation in English genitives across modality and genres. English Language and Linguistics 18(3). 471-496.

Gries, Stefan Th. 2013. Sources of variability relevant to the cognitive sociolinguist, and corpus as well as psycholinguistic methods and notions to handle them. Journal of Pragmatics 52. 5-16.

Heylen, Kris, Thomas Wielfaert, Dirk Speelman, \& Dirk Geeraerts. 2015. Monitoring polysemy: Word space models as a tool for large-scale lexical semantic analysis. Lingua 157. 153172.

Heylen, Kris \& Weiwei Zhang. 2019. From the cookbook of corpus-based lexical lectometry: A taste of Chinese. Paper presented at the 10th International Conference on Language Variation in Europe, ICLaVE-10, Leeuwarden, 26-28 June.

Hollmann, Willem B. 2013. Constructions in cognitive sociolinguistics. In Thomas Hoffmann \& Graeme Trousdale (eds.), The Oxford handbook of Construction Grammar, 491-509. 0xford: Oxford University Press.

Huang, Chu-Ren. 2009. Tagged Chinese Gigaword (Version 2.0 LDC2009T14). Web Download. Philadelphia: Linguistic Data Consortium.

Kristiansen, Gitte. 2003. How to do things with allophones: Linguistic stereotypes as cognitive reference points in social cognition. In René Dirven, Roslyn M. Frank \& Martin Pütz (eds.), Cognitive models in language and thought, CLR 24, 69-120. Berlin/New York: Mouton de Gruyter.

Kristiansen, Gitte. 2008. Style-shifting and shifting styles: A socio-cognitive approach to lectal variation. In Gitte Kristiansen \& René Dirven (eds.), Cognitive Sociolinguistics: Language variation, cultural models, social systems, 45-88. Berlin/New York: Mouton de Gruyter.

Kristiansen, Gitte. 2010. Lectal acquisition and linguistic stereotype formation. In Dirk Geeraerts, Gitte Kritiansen \& Yves Peirsman (eds.), Advances in Cognitive Sociolinguistics, 225 263. Berlin/New York: Mouton de Gruyter. 
Kristiansen, Gitte \& René Dirven. (eds.). 2008. Cognitive Sociolinguistics: Language variation, cultural models, social systems. Berlin/New York: Mouton de Gruyter.

Kristiansen, Gitte \& Dirk Geeraerts. (eds.). 2013. Contexts and usage in Cognitive Sociolinguistics. Journal of Pragmatics 52. 1-4.

Lippi-Green, Rosina. 1997. English with an accent: Language, ideology, and discrimination in the United States. London: Routledge.

Liu, Hua. 2019. Research on the construction and function of the Global Chinese Corpus. Jianghan Xueshu 1. 46-52.

Li, Xiaofan. 2004. Levels and classes of tone sandhi in Chinese dialects. Fangyan 1. 16-33.

$\mathrm{Li}, \mathrm{Yi}$, Benedikt Szmrecsanyi \& Weiwei Zhang. Submitted. The theme-recipient alternation in Mandarin Chinese: Tracking syntactic variation across seven centuries.

Pantos, Andrew J. 2014. Defining the cognitive mechanisms underlying reactions to foreign accented speech. In Martin Pütz, Justyna A. Robinson \& Monika Reif (eds.), Cognitive Sociolinguistics: Social and cultural variation in cognition and language use, 187-212. Amsterdam: John Benjamins.

Peirsman, Yves, Kris Heylen \& Dirk Geeraerts. 2010. Applying word space models to sociolinguistics: Religion names before and after 9/11. In Dirk Geeraerts, Gitte Kritiansen \& Yves Peirsman (eds.), Advances in Cognitive Sociolinguistics, 111-137. Berlin/New York: Mouton de Gruyter.

Polzenhagen, Frank \& René Dirven. 2008. Rationalist and romantic models in globalisation. In Gitte Kristiansen \& René Dirven (eds.), Cognitive Sociolinguistics: Language variation, cultural models, social systems, 237-299. Berlin/New York: Mouton de Gruyter.

Pütz, Martin, Justyna A. Robinson \& Monika Reif. 2014. Cognitive Sociolinguistics: Social and cultural variation in cognition and language use. Amsterdam: John Benjamins Publishing Company.

Ruette, Tom, Dirk Speelman \& Dirk Geeraerts. 2011. Measuring the lexical distance between registers in national varieties of Dutch. Paper presented at the International Conference on Pluricentric Languages, Universidade Católica Portuguesa, 15-17 September.

Röthlisberger, Melanie, Jason Grafmiller \& Benedikt Szmrecsanyi. 2017. Cognitive indigenization effects in the English dative alternation. Cognitive Linguistics 28(4). 673-710.

Sankoff, David \& Pierrette Thibault. 1981. Weak complementarity: Tense and aspect in Montreal French. In Brenda Johns \& David R. Strang (eds.), Syntactic change, 205-216. Ann Arbor: University of Michigan Press.

Schneider, Klaus P. 2014. Pragmatic variation and cultural models. In Martin Pütz, Justyna A. Robinson \& Monika Reif (eds.), Cognitive Sociolinguistics: Social and cultural variation in cognition and language use, 107-132. Amsterdam: John Benjamins.

Shi, Dingxu, Jingmin Shao \& Zhiyu Zhu. 2006. A comparison of Hong Kong Chinese and Standard Chinese. Hong Kong: Hong Kong Educational Publishing Company.

Shi, Dingxu, Jingmin Shao \& Zhiyu Zhu. 2014. A comparison of Hong Kong Chinese and Standard Chinese ( $2^{\text {nd }}$ edn.). Hong Kong: Hong Kong Educational Publishing Company.

Soares da Silva, Augusto. 2010. Measuring and parameterizing lexical convergence and divergence between European and Brazilian Portuguese. In Dirk Geeraerts, Gitte Kristiansen \& Yves Peirsman (eds.), Advances in Cognitive Sociolinguistics, 41-84. Berlin/New York: Mouton de Gruyter.

Speelman, Dirk, Stefan Grondelaers \& Dirk Geeraerts. 2003. Profile-based linguistic uniformity as a generic method for comparing language varieties. Computers and the Humanities 37(3). 317-337. 
Speelman, Dirk, Stefan Grondelaers \& Dirk Geeraerts. 2008. Variation in the choice of adjectives in the two main national varieties of Dutch. In Gitte Kristiansen \& René Dirven (eds.), Cognitive Sociolinguistics: Language variation, cultural models, social systems, 205-233. Berlin/New York: Mouton de Gruyter.

Stefanowitsch, Anatol \& Stefan Th. Gries. 2008. Channel and constructional meaning: A collostructional case study. In Gitte Kristiansen \& René Dirven (eds.), Cognitive Sociolinguistics: Language variation, cultural models, social systems, 129-152. Berlin/New York: Mouton de Gruyter.

Sun, Xiaojun. 2009. The social turn of Cognitive Linguistics. Waiguoyu 5. 47-51.

Szmrecsanyi, Benedikt. 2010. The English genitive alternation in a cognitive sociolinguistics perspective. In Dirk Geeraerts, Gitte Kritiansen \& Yves Peirsman (eds.), Advances in Cognitive Sociolinguistics, 141-166. Berlin/New York: Mouton de Gruyter.

Szmrecsanyi, Benedikt, Jason Grafmiller, Benedikt Heller \& Melanie Röthlisberger. 2016. Around the world in three alternations: Modeling syntactic variation in varieties of English. English World-wide 37(2). 109-137.

Szmrecsanyi, Benedikt, Jason Grafmiller \& Laura Rosseel. 2019. Variation-based distance and similarity modeling: A case study in World Englishes. Frontiers in Artificial Intelligence. https://doi.org/10.3389/frai.2019.00023.

Tian, Xiaoyu \& Weiwei Zhang. 2020. Chinese analytic causative constructions and their lectal variation: A multinomial logistic regression. Waiyu yu Waiyu Jiaoxue 3. 22-33.

Tian, Xiaoyu, Weiwei Zhang \& Dirk Speelman. 2022. Lectal variation in Chinese analytic causative constructions: What trees can and cannot tell us. In Dennis Tay \& Molly Xie Pan (eds.), Data analytics in Cognitive Linguistics: Methods and insights. Berlin/Boston: De Gruyter Mouton.

Tsou, Benjamin \& Olivia Kwong. 2015. LIVAC as a monitoring corpus for tracking trends beyond linguistics. In Benjamin Tsou \& Olivia Kwong (eds.), Linguistic corpus and corpus linguistics in the Chinese context, 447-471. Hong Kong: The Chinese University Press.

Wang, Huidi. 1999. Unique words in Singapore Mandarin: A social portrait of Singapore. Yangzhou Daxue Xuebao (Renwen Shehui Kexue Ban) 4. 44-51.

Wang, Xuan. 2017. Investigating the role of speaker attitudes in koinéisation in Hohhot, China. Asia-Pacific Language Variation 3(2). 232-270.

Weiner, E. Judith \& William Labov. 1983. Constraints on the agentless passive. Journal of Linguistics 19(1). 29-58.

Wolk, Christoph, Joan Bresnan, Anette Rosenbach \& Benedikt Szmrecsanyi. 2013. Dative and genitive variability in Late Modern English: Exploring cross-constructional variation and change. Diachronica 30(3). 382-419.

Wolf, Hans G., \& Frank Polzenhagen. 2009. World Englishes: A cognitive sociolinguistic approach. Berlin/New York: Mouton de Gruyter.

Wolf, Hans G., \& Frank Polzenhagen. 2014. Cognitive sociolinguistics in L2-variety dictionaries of English. In Martin Pütz, Justyna A. Robinson \& Monika Reif (eds.), Cognitive Sociolinguistics: Social and cultural variation in cognition and language use, 133-160. Amsterdam: John Benjamins.

Xiong, Liqin. 2020. Chinese listeners' perceptions of native and nonnative accents of standard Chinese: An experimental study. Madrid: Universidad Complutense de Madrid PhD dissertation.

Xu Baohua, Tang Zhenzhu \& Chen, Zhongmin. 1993. The taxonomy of Shanghai dialects. Fangyan 1. 14-30. 
Zhang, Jinwei. 2014. A sociophonetic study on tonal variation of the Wuxi and Shanghai dialects. Amsterdam: Netherlands Graduate School of Linguistics.

Zhang, Tianwei. 2019. Review of recent advances in Cognitive Sociolinguistics: Trend and characteristics. Waiyu Jiaoxue 3. 26-31.

Zhang, Weiwei, Dirk Geeraerts, \& Dirk Speelman. 2015. Visualizing onomasiological change: Diachronic variation in metonymic patterns for WOMAN in Chinese. Cognitive Linguistics 26(2). 289-330.

Zhang, Weiwei, Dirk Geeraerts \& Dirk Speelman. 2018. (Non)metonymic expressions for GOVERNMENT in Chinese: A mixed-effects logistic regression analysis. In Dirk Speelman, Kris Heylen \& Dirk Geeraerts (eds.), Mixed-Effects regression models in linguistics (Quantitative methods in the humanities and social sciences series), 117-146. Cham: Springer.

Zhang, Weiwei, Kris Heylen \& Dirk Geeraerts. 2019. Analyzing lexical variation in regional varieties of Chinese: A concept-based approach. Paper presented at the 15th International Cognitive Linguistics Conference. Nishinomiya, 6-11 August.

Zhang, Weiwei, Dirk Speelman \& Dirk Geeraerts. 2011. Variation in the (non)metonymic capital names in Mainland Chinese and Taiwan Chinese. Metaphor and the Social World 1(1). 90112.

Zhang, Weiwei \& Fang Wang. 2017. An exemplar-based conceptual space of Chinese passives with rang and gei. Waiyu yu Waiyu Jiaoxue 6. 22-33.

Zhang, Hui \& Hongyin Zhou. 2010. New development of Cognitive Linguistics - Cognitive Sociolinguistics. And a review of Cognitive Sociolinguistics (Kristiansen \& Dirven 2008). Waiyu Xuekan 3. 36-42.

Zhao, Hui. 2017. Language variation and social identity in Beijing. London: Queen Mary University of London PhD dissertation.

Zhao, Hui. 2019. Social meaning in the perception of neutral tone variation in Putonghua. Asia Pacific Language Variation 4(2). 161-196.

Zhao, Hui, \& Hong Liu. 2020. (Standard) language ideology and regional Putonghua in Chinese social media: a view from Weibo. Journal of Multilingual and Multicultural Development. DOI: $10.1080 / 01434632.2020 .1814310$.

Zhou, Hongyin. 2012. Recent advances in Cognitive Sociolinguistic research: Review of Advances in Cognitive Sociolinguistics. Waiguoyu 5. 85-89. 